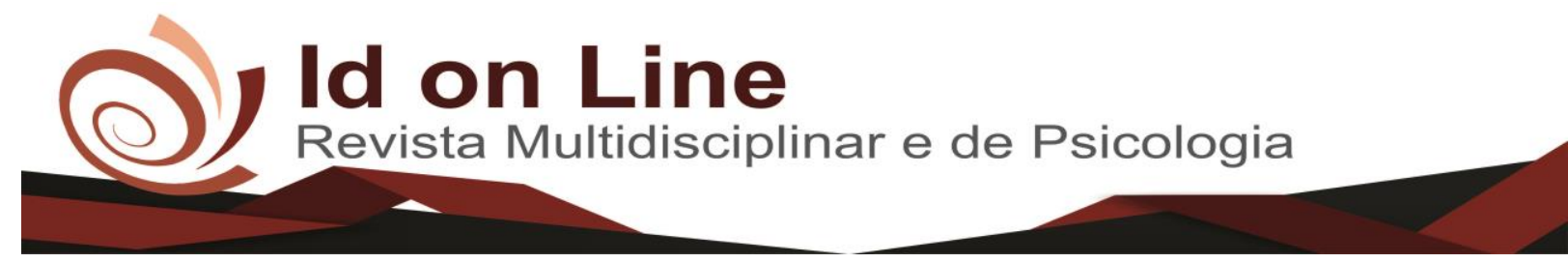

Comment

\title{
O Ensino de Gramática no Ensino Fundamental: Dificuldades e Possibilidades
}

\author{
Joelma dos Santos Barbosa Linhares Garcia ${ }^{l}$
}

\begin{abstract}
Resumo: Este manuscrito procura refletir sobre o trabalho com a gramática no ensino fundamental, na perspectiva de conhecer a importância deste estudo ser realizado de uma forma dinâmica e significativa para o aluno e quais as dificuldades e possibilidades para esse trabalho. Para a realização deste estudo foram utilizados como base teórica os trabalhos de pesquisadores como Campos (2014), Kleiman (2014), Meyer (1980), Rojo (2000), Travalia (2008) entre outros. O conteúdo abordado foram conjunções subordinativas adverbiais. Estas são vistas por grande parte dos alunos e por pessoas que já encerraram seus estudos, como sendo um conteúdo difícil de aprender, extenso e sem função social. Esta pesquisa, no entanto, busca mostrar que, a partir da utilização do campo semântico, e juntamente com o método, denominado por nós, como semântico - associativo* pode se tornar uma experiência bastante significativa para o aluno. Acreditamos que as orientações didáticas apresentadas podem auxiliar o aluno na construção de sua competência linguística, fazendo com que ele possa expressar melhor suas ideias na escrita, saiba articular as sequências e os enunciados em seus textos de maneira mais coerente e coesa, e estabelecer as relações de sentido pretendidas.
\end{abstract}

Palavras-chave: Ensino de Gramática; Ensino fundamental; Difuculdades; Possibilidades; Interação.

\section{O Ensino de Gramática no Ensino Fundamental: Dificuldades e Possibilidades}

\begin{abstract}
Resumo: Este artigo procura refletir sobre o trabalho com a gramática no ensino fundamental, na perspectiva de conhecer a importância deste estudo ser realizado de uma forma dinâmica e significativa para o aluno e quais as dificuldades e possibilidades para esse trabalho. Para a realização deste estudo foram utilizados como base teórica os trabalhos de pesquisadores como Campos (2014), Kleiman (2014), Meyer (1980), Rojo (2000), Travalia (2008) entre outros. O conteúdo abordado foram conjunções subordinativas adverbiais. Estas são vistas por grande parte dos alunos e por pessoas que já encerraram seus estudos, como sendo um conteúdo difícil de aprender, extenso e sem função social. Esta pesquisa, no entanto, busca mostrar que, a partir da utilização do campo semântico, e juntamente com o método, denominado por nós, como semântico - associativo* pode se tornar uma experiência bastante significativa para o aluno. Acreditamos que as orientações didáticas apresentadas podem auxiliar o aluno na construção de sua competência linguística, fazendo com que ele possa expressar melhor suas ideias na escrita, saiba articular as sequências e os enunciados em seus textos de maneira mais coerente e coesa, e estabelecer as relações de sentido pretendidas.
\end{abstract}

Palavras-chave: Ensino de Gramática; Ensino fundamental; Difuculdades; Possibilidades; Interação.

\footnotetext{
${ }^{1}$ Doutoranda em Ciências da Linguagem na Universidade Católica de Pernambuco (UNICAP). E-mail: jsblinharesgarcia@ hotmail.com.
} 


\section{Introdução}

A língua é organizada e perpetuada através dos tempos por meio de sua gramática, um conjunto de regras que descreve e prescreve o funcionamento da língua.

Este trabalho busca apresentar uma sequência didática prática que possibilite ao aluno entender a função das conjunções subordinativas e aprender gramática de forma reflexiva, lúdica e produtiva. Partindo do seu conhecimento prévio, é possível criar estratégias que lhe possibilite uma forma mais fácil de aprender e de lembrar-se das relações de sentido estabelecidas pelas conjunções. A hipótese é que a partir do método semântico- associativo, criado e sistematizado para este trabalho, a imagem de que gramática é difícil, chata e sem utilidade no cotidiano, seja desmistificada.

São inúmeras dificuldades de leitura e escrita que os alunos têm durante e após o período escolar. Diariamente, o professor em sala de aula tem que se desdobrar em busca de métodos mais eficazes, estratégias e práticas que favoreçam a aprendizagem de seus alunos.

$\mathrm{Na}$ escola campo de estudo, durante a pesquisa, $75 \%$ dos professores de Língua Portuguesa afirmaram não gostar do conteúdo Orações Subordinadas e de lecionar também outros conteúdos gramaticais. Em relação aos alunos, $90 \%$ deles o consideraram algo difícil de aprender. Conjunções subordinadas adverbiais foram o conteúdo escolhido para ser objeto de ensino da sequência didática apresentada, devido à imagem negativa que possui entre grande parte das pessoas, a sua aprendizagem é dificultada. Nas escolas, é comum encontrar professores de Língua Portuguesa que abominam o ensino da gramática, assim como docentes que suprimem o conteúdo períodos compostos por subordinação em sua prática. Consequentemente, este sentimento é transmitido aos alunos, influenciando na aversão demonstrada pela maioria das pessoas em relação aos estudos gramaticais. Outro empecilho é a metodologia adotada. Durante as aulas expositivas tradicionais, muitos professores limitamse a expor as nomenclaturas e exemplos de conjunções presentes em frases sem relação com a realidade. Essa atividade é uma proposta redutora e limitada. O ensino de Gramática não pode mais ser restrito à imposição de um conjunto de regras e nomenclaturas, mas sim proporcionar uma aprendizagem consciente do seu sentido e do seu uso prático no cotidiano.

Diante dessa problemática, as questões que nortearam este trabalho foram: Quais os motivos que fazem com que as conjunções subordinadas adverbiais sejam consideradas um conteúdo difícil? Como ensinar as conjunções subordinadas de forma lúdica e prática? Como o 
cordel pode facilitar a aprendizagem deste conteúdo pelos alunos? Qual a importância de estudar as conjunções subordinadas adverbiais? Os métodos tradicionais garantem uma aprendizagem efetiva?

Este trabalho pretende contribuir substancialmente para mudar a imagem negativa atrelada ao ensino das orações subordinadas adverbiais e facilitar sua aprendizagem, devido a sua importância para a prática da leitura e da produção de textos. Além disso, pretende-se verificar a eficácia do método semântico- associativo para o ensino de gramática.

\section{O Ensino de Gramática no Ensino Fundamental II}

O ensino de gramática da Língua Portuguesa no Ensino Fundamental apresenta algumas características específicas que se relacionam à organização dessa etapa da escolarização. Como exemplo tem-se a escolha dos conteúdos convertidos em objetos de ensino, a progressão gradativa desses objetos nas séries do Ensino Fundamental e a maneira de abordar os conteúdos de forma lúdica e motivadora. A abordagem deve ser bem sistematizada para fazer que os estudantes consigam aprender os conceitos fundamentais que servirão de alicerce para estudos posteriores durante o Ensino Médio e Superior. A sequência didática é substancial para esta sistematização. Segundo os autores Dolz, Noverraz e Schneuwly (2004, p. 97), a "sequência didática consiste em uma organização global e progressiva do ensino e das aprendizagens, durante um período de tempo, levando-se em consideração o gênero estudado e o ritmo de aprendizagem dos estudantes".

A sequência apresentada foi realizada no $8^{\circ}$ ano do Ensino Fundamental II anos finais. Neste trabalho, defendemos a ideia de que ensinar gramática em sala é importante e que é possível fazer isso de uma forma dinâmica e participativa que possibilite a reflexão para buscar o sentido e a aplicação do conhecimento para tornar o aluno um bom leitor e produtor de textos.

O ensino da gramática deve ter como foco a utilização da língua nas práticas sociais articuladas com a produção e leitura de textos. Nas atividades propostas, além da preocupação com o conteúdo gramatical, há também um enfoque no uso social da língua, com suas exigências, características contextuais e limitações. Concordamos com Travaglia (2008), quando diz que: 
A perspectiva textual tem a possibilidade de fazer com que a gramática seja flagrada em seu funcionamento, evidenciando que a gramática é a própria língua em uso. Isto muda também o conceito de gramática que será usado no ensino de língua materna, pois passa-se a ver como integrando a gramática tudo que é utilizado e/ou interfere na construção e uso dos textos em situações de interação comunicativa e não só o conhecimento de alguns tipos de unidades e regras da língua restritas ao nível morfológico. (TRAVAGLIA, 2008, p. 101).

Um dos maiores problemas enfrentados pela gramática atualmente é provar a sua funcionalidade nas atividades cotidianas e a sua eficácia no desenvolvimento da aprendizagem. Como afirma Meirelles:

\begin{abstract}
Conhecer a organização do sistema linguístico, assim como as regras de funcionamento de sua gramática e as formas de classificação dos elementos que a constituem é essencial. E, basicamente, por duas razões. A primeira delas é que esse estudo nos permite conhecer uma certa tradição- muito difundida e historicamente importante- no tratamento da língua. A segunda razão é que compreender a organização de sistema linguístico- suas categorias e suas inter-relações- permite que se entendam os conceitos que o percorrem. (MEIRELLES, 1991 apud KLEIMAN, 2014, p. 9)
\end{abstract}

Muitas vezes, a aula de gramática é apenas a exposição de um conjunto de regras, conceitos, memorização das nomenclaturas, exemplos sem significação, seja para o aluno ou para o professor. Não são levadas em conta a funcionalidade e o sentido das palavras. O professor ensina da forma que aprendeu, pois é impossível ensinar o que não se sabe. Ou seja, para facilitar a compreensão do aluno, é preciso que o professor tenha formação adequada para que ele possa reinventar a sua prática, perceber as necessidades dos alunos e poder intervir sobre elas. Como aponta Rojo (2000), quando afirma que grande parte dos cursos de licenciatura em Letras não aborda as teorias sobre língua/linguagem e ensino-aprendizagem indicadas e exigidas para o ensino atual. O professor de Língua vive no dilema entre ensinar o velho considerado como "errado" e ensinar o novo, algo que ele ainda não conhece e nem está sendo formado para isto.

Antigamente, o ensino de Língua era baseado na exposição, classificação e nos exercícios baseados na memorização das regras gramaticais. Pensava-se que, munidos dessas regras, que eram exemplificadas através de frases, consequentemente os alunos produziriam bons textos. Mas não é bem assim, pois, para chegar ao sentido pretendido pelo locutor, é necessário ter um bom vocabulário, pontuar bem e dar informatividade ao texto, conhecer a situação discursiva em que o texto está inserido, saber utilizar bem os conectores no 
encadeamento das ideias e introduzir os tempos verbais adequados para a realização da progressão textual.

Com o tempo, vieram novas propostas de ensino e ensinar "gramática" passou a ser sinônimo de retrocesso. Muitos professores baniram o seu ensino esperando por novas formas de ensinar os alunos através do texto. Mas as orientações e direcionamentos sobre esse "novo jeito de ensinar" não são claros e não mostram maneiras práticas e concretas para que o professor possa desenvolvê-las em sala. Não há uma fórmula ou receita pronta e o professor de Língua materna realiza a sua prática baseado em hipóteses.

Se, por um lado, os alunos que estudaram através dos compêndios gramaticais tradicionais, nem sempre aprendiam a ler, a escrever e a refletir sobre a sua própria língua, hoje em dia a maioria dos alunos não consegue identificar um substantivo ou um verbo no texto, ou até utilizá-los de maneira coerente em suas produções textuais. As novas teorias são indicadas pelos currículos para serem trabalhadas na escola, mas, na prática, ainda não conseguiram solucionar muitos dos graves problemas relacionados à aprendizagem de Língua materna.

De acordo com Antunes (2003, p.87) a maior preocupação do ensino descritivo da gramática é citar regras que formam frases e fazer com que o aluno venha reconhecer o nome de cada elemento que a constrói, e não de fazer o aluno perceber o verdadeiro sentido que determinado elemento exerce nessa frase e as inúmeras possibilidades que o mesmo, possa exercer em um texto, ou seja, não analisa os efeitos que esses elementos provocam tanto em textos orais quanto em textos escritos.

Antunes (2003) ainda reforça que a questão maior não é ensinar ou deixar de ensinar a gramática, mas sim discernir o que se objetiva ensinar, uma vez que "a gramática existe não em função de si mesma, mas em função do que as pessoas escrevem nas práticas sociais da língua" (ANTUNES, 2003, p.88 -89).

A gramática por si só não tem nenhum valor, a não ser que ela de alguma forma esteja inserida em algum léxico, e para que isso aconteça é necessário que haja comunicação e interação e situações para determinar a que regra se aplica.

Alguns querem que o seu estudo seja abolido dos currículos escolares. Mas segundo Vygotsky (1989, p. 86) “o estudo da gramática é de grande importância para o desenvolvimento mental da criança”. O linguista Mário Perini (2002) afirma que, muito embora o estudo da gramática seja muito importante para a formação das habilidades intelectuais, a escola não 
consegue desenvolver no aluno a autonomia do pensamento. Ou seja, faltam métodos e práticas aplicáveis e mais eficazes.

Atualmente procura-se estudar Português através do texto, mas de que formas podemos utilizar melhor este recurso pedagógico? O que há de positivo e de negativo nas práticas tradicionais e modernas? A gramática tem lugar na escola? Este trabalho surgiu da necessidade de responder a estes questionamentos.

Segundo Travalia (2008, p. 34), tanto o ensino descritivo como o normativo podem ser utilizados em sala de aula, contanto que sejam redimensionados diferentemente do modo como tem sido o ensino de Língua. Mas a contradição de tudo isso é que as provas de concursos e vestibulares continuam exigindo que o aluno domine nomenclaturas, aspectos e convenções da norma culta; privilegiando aspectos estruturais do texto. Os professores que admitem ensinar gramática em sala sofrem muito preconceito dos colegas. A metodologia do ensino de Gramática em sala de aula é um dos maiores problemas enfrentados pelo professor de Língua Portuguesa em seu ofício diário. Acreditamos que é possível equilibrar as práticas tradicionais e as atuais, sem julgá-las inferiores ou superiores.

Ensinar Gramática é importante para garantir ao cidadão um maior acesso aos bens sociais, culturais e econômicos. A gramática é uma valiosa ferramenta pedagógica que auxilia na interpretação, reflexão sobre os mais variados recursos linguísticos, produção de textos e na oralidade.

[...] pedagogicamente, sugerimos que se considere a gramática como sendo o estudo das condições linguísticas da significação, que estão relacionadas a elementos como para quem, como, por quê e quando as expressões linguísticas significam o que significam, por causa da influência de fatores sociais, históricos, culturais e ideológicos (no sentido lato de como vemos os elementos do mundo, ou seja, nossa visão de mundo, inclusive nossas crenças). (TRAVAGLIA 2009 e 2011, s/p)

O ensino de gramática através da metodologia adequada e realizada de forma bem orientada é muito importante para desenvolver a competência comunicativa dos alunos, facilitando assim a aprendizagem efetiva de novos saberes, como afirma Perini (2002, p. 31)

$\mathrm{O}$ estudo da gramática pode ser um instrumento para exercitar o raciocínio e a observação; pode dar a oportunidade de formular e testar hipóteses; e pode levar à descoberta de fatias dessa admirável e complexa estrutura que é a língua natural. $\mathrm{O}$ aluno pode sentir que está participando desse ato de descoberta, através de sua contribuição à discussão, ao argumento, à procura de novos exemplos e contraexemplos cruciais para a testagem de uma hipótese dada. 
Em sala de aula, a ordem é trabalhar através do gênero textual e analisar os recursos lingüísticos que envolvem a sua produção e utilização. Mas, para que as características do gênero sejam aprendidas, é necessário ensinar gramática. É preciso saber os conceitos, os tipos, modos e tempos dos verbos, os contextos em que podem ser utilizadas determinadas classes de palavras, as regras de utilização das preposições, conjunções e assim por diante para poder produzir o gênero.

\begin{abstract}
Na aula de gramática, começa-se pelo nível micro, das unidades menores, da palavra à frase, primeiramente por uma questão didática, porque essa progressão organiza o trabalho apresentado unidades de mais fácil compreensão do aluno, e, segundo, por uma questão de coerência científica, já que a frase é a unidade da análise gramatical. Porém, a todo momento é possível sair desse nível e elaborar questões fonológicas, ortográficas, semânticas, enunciativas, discursivas com os alunos. (KLEIMAN, 2014, p. 148)
\end{abstract}

Segundo Kleiman (2014, p 40), o psicólogo russo, Lev Vigotsky, um dos grandes estudiosos do desenvolvimento e da aprendizagem da criança, afirmava que em seus estudos foi constatado que a gramática é muito importante para o desenvolvimento intelectual da criança. A partir dela, a criança consegue estabelecer novas relações, conceber novas estruturas, possibilitando a modificação do próprio conhecimento e entender o funcionamento da língua.

Ela sozinha não tornará o aluno um bom leitor e produtor de textos, mas contribuirá substancialmente para uma melhor reflexão e utilização dos recursos linguísticos necessários para a comunicação. A Língua é um instrumento de poder. Negar este conhecimento ao aluno é relegá-lo à margem social, como afirma o linguista Americano Dwight Bolinger, a língua "é uma arma carregada. Saber usá-la é ter poder" (KLEIMAN, 2014, p. 9). Por outro lado, sabemos que ensinar a gramática do modo tradicional não é o caminho mais indicado para tornar o aluno leitor e produtor de textos, mas que é difícil transformar a teoria em prática.

\title{
Metodologia
}

O estudo, ora comentado, foi realizado durante as aulas de Língua Portuguesa e o conteúdo escolhido para a análise consta no currículo do estado de Pernambuco chamado de OTMs (Orientações Teórico- Metodológicas). 
A metodologia de pesquisa utilizada foi a pesquisa-ação. Este método une a teoria à prática. Através dela o professor pode, durante o desenvolvimento de sua pesquisa, intervir em sua própria realidade de sala de aula, transformando as turmas em que leciona em objetos de pesquisa. Utilizamos também para realizar este trabalho uma técnica de estudo denominada por nós pesquisadoras como método semântico- associativo. Ele consiste em utilizar o conhecimento prévio do aluno para alicerçar novos saberes, associando o sentido estabelecido pelas conjunções às letras inicias de suas nomenclaturas que estarão contidas em palavras ou frases que sejam significativas para o aluno ou façam parte do seu cotidiano. Como o nome das conjunções subordinativas estão diretamente relacionados à relação de sentido que estabelecem, os alunos então conseguiram relacionar o nome da conjunção ao sentido que expressam.

Ao lembrar da palavra, automaticamente buscaram na memória em quais contextos semânticos a conjunção poderia ser utilizada. Então, quando os estudantes, por ventura, necessitarem desse conhecimento, eles poderão acessá-lo na memória e lembrar-se do signo linguístico $($ Significante $=$ Letra inicial /palavra ou frase + significado $=$ relação semântica estabelecida pela conjunção).

\section{Método Tradicional de Ensino de Gramática}

Na turma do oitavo ano A o método empregado pelo professor para expor o conteúdo foi o método tradicional com a apostila e explicação oral como no fragmento exposto abaixo:

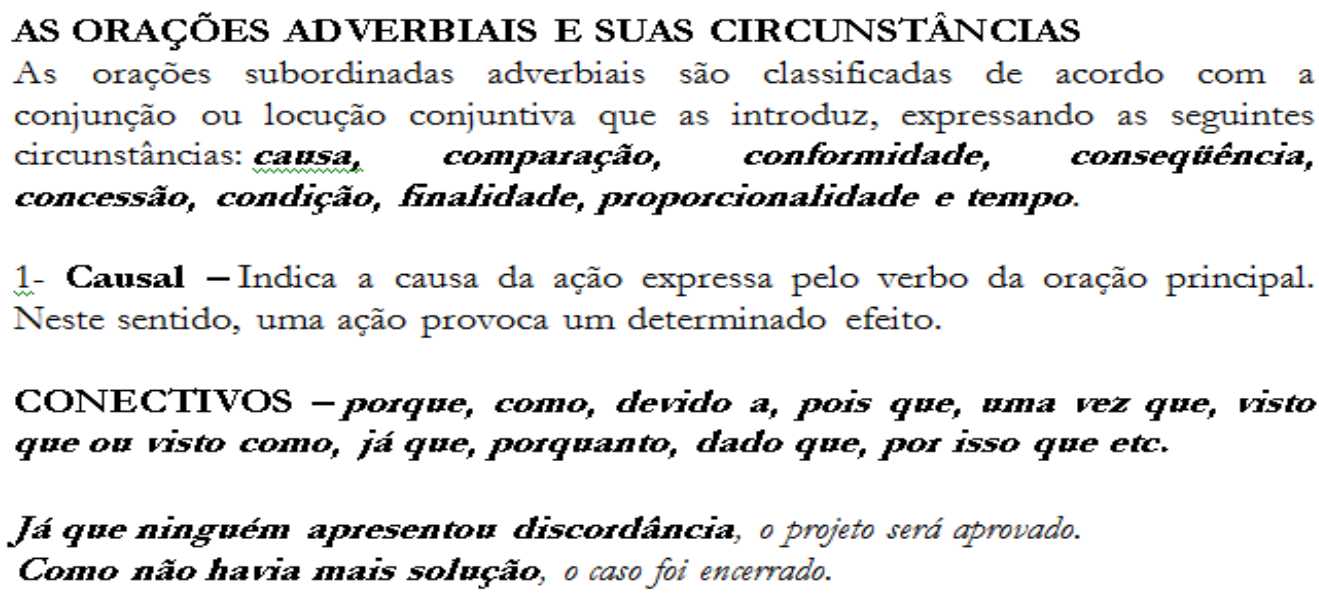

- Realização de uma Avaliação escrita; 


\section{Considerações Finais}

Com as atividades apresentadas, não foi nosso objetivo indicar receitas que solucionarão todos os problemas de aprendizagem do aluno, mas sim partilhar uma experiência exitosa que pode ser utilizada por todos os professores em suas salas de aula, respeitando a heterogeneidade das turmas e servir como um ponto de partida para estudos posteriores.

Não estamos querendo afirmar que todas as aulas expositivas não são adequadas, mas que existem outros métodos e sequencias didáticas que podem ser aplicados em sala de aula; e consequentemente obter êxito.

Chegamos à conclusão que o método semântico-associativo conseguiu fazer com que, os alunos do oitavo B demonstrassem mais interesse pelo conteúdo e participassem mais ativamente das atividades em comparação aos alunos do oitavo ano $\mathrm{A}$, na qual o método tradicional foi utilizado. Os alunos do oitavo ano B, ao final das atividades, consideraram o conteúdo fácil e objetivo, conseguiram identificar os conectivos e relacionar os seus sentidos de acordo com determinados contextos, entenderam a relação de dependência estabelecida entre as orações, e assimilaram que, portanto, "uma oração depende da outra", por isso será uma oração subordinada. Ou seja, é possível mudar a imagem da gramática em sala de aula a partir da aplicação de outros métodos. Acreditamos também que uma das causas do êxito deste trabalho foi a professora regente se dispor a ouvir seus alunos, identificar suas necessidades e buscar formas de intervir sobre o problema.

\section{Referências}

ANTUNES, Costa, Irandé, 1937. Aula de Português encontro e interação. São Paulo: Parábola Editorial, 2003.

CAMPOS, Elísia Paixão de. Por um novo ensino de gramática: orientações didáticas e sugestões de atividades. 1. ed. Goiânia: Cânone Editorial, 2014.

GERALDI,J. W. Portos de passagem.São Paulo-SP:Martins Fontes, 1991.

. Concepções de linguagem e ensino de português. In: $O$ texto na sala de aula: leitura e produção. 2. ed. Cascavel: Assoeste, 1984. 
KLEIMAN, Angela; SEPULVEDA, Cida. Oficina de gramática: metalinguagem para principiantes. 2. Ed. Campinas, SP: Pontes Editores, 2014.

MELO, Gladstone Chaves de. Gramática fundamental da língua portuguesa. Rio de Janeiro: Ao Livro Técnico, 1978;

PERINI, Mário A. Gramática descritiva do português. São Paulo: Ática, 2002.

ROJO, R. (2005) "Gêneros de discurso/texto como objeto de ensino de línguas: um retorno ao trivium?" (mimeo).

TRAVAGLIA, Luiz Carlos. Gramática e interação: uma proposta para o ensino de gramática. São Paulo: Cortez, 2008.

Glossário Ceale: Gramática. Disponível em: <http://ceale.fae. ufmg.br/app/webroot/glossarioceale/verbetes/gramatica> Acessado em 20 de Abril de 2018;

Gramática ensino plural. São Paulo: Cortez, 2007.

VYGOTSKY, L. S. Pensamento e linguagem. São Paulo: Martins Fontes, 1989

\section{Como citar este artigo (Formato ABNT):}

GARCIA, Joelma dos Santos B. L. O Ensino de Gramática no Ensino Fundamental: Dificuldades e Possibilidades. Id on Line Rev.Mult. Psic., 2018, vol.12, n.40, p.650-659. ISSN: 1981-1179.

Joelma dos Santos Barbosa Linhares Garcia ${ }^{1}$

Recebido: 07/05/2018

Aceito 11/05/2018 